\title{
Correction to: Pediatric ileocolic intussusception: new observations and unexpected implications
}

\author{
Larry A. Binkovitz ${ }^{1}$ Amy B. Kolbe ${ }^{1} \cdot$ Robert C. Orth $^{2} \cdot$ Nadia F. Mahmood $^{2} \cdot$ Prabin Thapa $^{3} \cdot$ Nathan C. Hull $^{1}$. \\ Paul G. Thacker ${ }^{1} \cdot$ Christopher Moir $^{4}$
}

Published online: 25 January 2019

(C) Springer-Verlag GmbH Germany, part of Springer Nature 2019

Correction to: Pediatric Radiology (2019) 49:76-81

https://doi.org/10.1007/s00247-018-4259-9

In this article, the fourth author's name is misspelled. The correct spelling, as shown above, should be "Nadia F. Mahmood."

Publisher's note Springer Nature remains neutral with regard to jurisdictional claims in published maps and institutional affiliations.

The online version of the original article can be found at https://doi.org/ $10.1007 / \mathrm{s} 00247-018-4259-9$

$\triangle$ Larry A. Binkovitz

binkovitz.larry@mayo.edu

1 Division of Pediatric Radiology, Mayo Clinic,

2107 Folwell Ridge St. SW,

Rochester, MN 55902, USA

2 Department of Radiology,

Texas Children's Medical Center,

Houston, TX, USA

3 Department of Biostatistics, Mayo Clinic,

Rochester, MN, USA

4 Division of Pediatric Surgery, Mayo Clinic,

Rochester, MN, USA 